\title{
Selection of highly virulent entomopathogenic fungal isolates to control the greenhouse aphid species in Iraq
}

\author{
Akram A. Mohammed ${ }^{1 *}$, Jamal H. Kadhim ${ }^{1}$ and Zahid N. A. Kamaluddin ${ }^{2}$
}

\begin{abstract}
Aphids are one of the major insect pests of greenhouses and field crops worldwide. Several species of entomopathogenic fungi (EPF), including Lecanicillium spp. Beauveria bassiana, Isaria fumosorosea and Metarhizium anisopliae, have been developed commercially to control aphid species. However, there are no commercial products based on EPF that have been registered in Iraq. This study, therefore, was conducted to evaluate the virulence of four isolates of EPF, including, $B$. bassiana, Lecanicillium lecanii, M. anisopliae and Chaetomium globosum to select the highly virulent ones against the greenhouse aphids. Although the isolate of $L$. lecanii had the highest virulence against all tested aphid species in the laboratory bioassay, Myzus persicae Sulz and Aphis gossypii Gloy were more susceptible than Aphis fabae and Macrosiphum euphorbiae to infection with L. lecanii. Mortality caused by L. lecanii 7 days post-treatment with $10^{8}$ conidia $\mathrm{ml}^{-1}$ was $100 \%$. Further experiments in the greenhouses showed that L. lecanii significantly reduced the density of both $M$. persicae and $A$. gossypii 5 days after fungal applications. This isolate shows a promise for development of an alternative control agent against M. persicae and A. gossypii in Iraq.
\end{abstract}

Keywords: Aphids, Lecanicillium spp., Mortality, Biological control, Iraq

\section{Background}

Vegetable production in greenhouses is very common in Iraq, providing plentiful food and ornamental crops; however, this allows for a rapid spread of insect pests and microbial diseases. Aphids (Hemiptera: Aphididae) are some of the most serious and damaging insect pests, because they cause direct damage by feeding directly on crops and indirectly damage them through virus transmission (Blackman and Eastop 2007). In Iraq, aphids seriously impact several greenhouse crops, especially cucumber, eggplant, tomato and potato (Tarek 2013). The melon aphid (Aphis gossypii), the green peach aphid (Myzus persicae), the potato aphid (Macrosiphum euphorbiae) and the black bean aphid (Aphis fabae) are four of the most common and important aphid pest species of greenhouse crops in Iraq (Jasman et al. 2016). All these aphid species are extremely polyphagous and

\footnotetext{
* Correspondence: akrama.abodarb@uokufa.edu.iq

${ }^{1}$ Plant Protection Department, University of Kufa, Najaf, Iraq

Full list of author information is available at the end of the article
}

vectors of large numbers of plant viruses (Chan et al. 1991). Chemical insecticides are the most common control method of aphid species, but their use results in insecticide residues, high levels of insecticide resistance and high costs (Bielza 2008; Gao et al. 2012). These difficulties in using synthetic insecticides to manage aphid populations have led to a growing interest in novel and effective alternatives like biological control including the use of entomopathogenic fungi (EPF).

There is an interest in the commercial development of EPF (Milner 1997) because they have the capability to infect aphids under natural conditions (Latgé and Papierok 1988; Hajek and St Leger 1994). There are about 60 biocontrol products, including 38 species or varieties of EPF, which have been developed and used as biocontrol agents against insect pests around the world (Faria and Wraight 2007). However, there are no commercial microbial pesticides based on EPF registered to control aphids in Iraq. Natural epizootics of aphids are usually caused by entomophthoralean fungi such as 
Pandora neoaphidis (Roy et al. 2005) as well as by hypocrealean fungi such as Lecanicillium spp. and Beauveria bassiana (Milner 1997; Li and Sheng 2007).

Many research studies have been conducted on the potential control of aphids with EPF. Kim and Kim (2008) tested the efficacy of six isolates of EPF collected in Korea, including B. bassiana, Isaria fumosorosea and Lecanicillium attenuatum against the cotton aphid, A. gossypii. An isolate of $L$. attenuatum CS625 had the highest virulence against $A$. gossypii. Various isolates of EPF such as Lecanicillium lecanii, Isaria farinosus, $B$. bassiana, Metarhizium anisopliae, Cordyceps scarabaeicola and Nomuraea rileyi were screened for controlling A. gossypii and M. persicae. Among the tested ones, $L$. lecanii showed the highest virulent pathogenicity for both A. gossypii and M. persicae ( $\mathrm{Vu}$ et al. 2007). In addition, B. bassiana and I. fumosorosea showed high efficacy against Phorodon humuli (Schrank) (Dorschner et al. 1991), Aphis craccivora Koch and Bemesia tabaci (Gennadius) (Zaki 1998). Mesquita et al. (1996) reported that different species/isolates of EPF induced similar mortalities in the Russian wheat aphid (Diuraphis noxia) even though these isolates were from different host insects. In contrast, Vandenberg (1996) found that isolates of any individual fungal species had different efficacy against the same cohort of the host aphid.

Despite the many studies in other countries around the world, there are few studies on the control of aphids with EPF in Iraq. Thus, the objective of this study was to evaluate different isolates of Iraqi EPF that originated from different insect hosts, against the greenhouse aphids in the laboratory. Based on the efficacy results of the laboratory trials, the best isolate was evaluated against $A$. gossypii and $M$. persicae on cucumber in greenhouse trials.

\section{Materials and methods Aphid culture}

Colonies of $M$. persicae, M. euphorbiae, A. gossypii and $A$. fabae were collected initially from the greenhouses at the Faculty of Agriculture, University of Kufa, Iraq, in 2016. The aphids were identified under a light compound microscope, using polyphagous aphid keys (Blackman and Eastop 2000). Aphid cultures were established on their main host plants (M. persicae on cucumber, A. gossypii on melon, $A$. fabae on beans and M. euphorbiae on potato) in $45 \times$ $45 \times 45 \mathrm{~cm}$ cages at $23 \pm 2{ }^{\circ} \mathrm{C}$ and with $16: 8$-h daily photoperiod for several generations. Plants were replaced every 2 weeks by healthy 4-5-week-old plants. To produce even-aged nymphs, adult aphids were transferred onto 2-week-old cucumber leaves with a fine camel hair brush and maintained on the plant for $6 \mathrm{~h}$. The adults were then removed and the newborn nymphs were left to develop on the cucumber leaf until use.

\section{Source and preparation of fungal isolates}

Four isolates of EPF (Table 1) were used in this study. Isolates were never isolated more than three times from the source and culture methods followed $(\mathrm{Vu}$ et al. 2007). The EPF were cultivated on potato dextrose agar (PDA) or Sabouraud's agar at $25^{\circ} \mathrm{C}$. Aerial conidia were harvested from 10-day-old cultures by adding $12 \mathrm{ml}$ of $0.02 \%$ Tween 80 to culture agar plates and gently scraping the surface of the cultures with a sterile inoculating loop to dislodge the conidia from the surface of the agar plates. The conidial suspension was pipetted from the plate and filtered through three layers of cheesecloth. The number of conidia in the suspension was determined using a haemocytometer (Neubauer improved, Superior Marienfeld, Germany). The resulting suspension was diluted to the desired concentrations with 0.02\% Tween 80 (BDH Chemicals Ltd., Poole, UK) as required. The viability of the conidia was determined by spraying $0.1 \mathrm{ml}$ of $1 \times 10^{6}$ conidia ml ${ }^{-1}$ on a sterile Petri dish with $1.5 \%$ Sabouraud dextrose agar (SDA). The dishes were sealed by a parafilm and incubated at $20{ }^{\circ} \mathrm{C}$, $90 \pm 2 \%$ RH and a photoperiod of 16:8 (L:D) h. After $24 \mathrm{~h}$, the number of germinated spores per 100 spores of each plate was assessed under the microscope (400× magnification). Germination was considered positive when the length of the germ tube was at least half the spore length. The viability exceeded $90 \%$ for all isolates.

\section{Obtaining a uniform age of aphids}

In order to produce even-aged third instar nymphs of each aphid species for use directly in all bioassays, adult aphids were transferred from the stock cultures onto 3 -week-old cucumber (20 adults per plant) using two 3-cm-diameter clip-cages and were allowed to produce

Table 1 Original host and geographical origin of Iraqi entomopathogenic fungi used in this study

\begin{tabular}{lll}
\hline Species & Original host & Geographic origin and date of isolation \\
\hline B. bassiana & Hemiptera: Scutelleridae: Eurygaster integriceps & Najaf, 2009 \\
L. lecanii & Hemiptera: Aphididae: Myzus persicae & Basra, 2011 \\
M. anisopliae & Coleoptera: Tenebrionidae: Tribolium castaneum & Baghdad, 2007 \\
C. globosum & Lepidoptera: Bombycidae: Bombyx mori & Najaf, 2014 \\
\hline
\end{tabular}


nymphs for $12 \mathrm{~h}$ in a growth chamber at $20{ }^{\circ} \mathrm{C}, 75 \pm 2 \%$ $\mathrm{RH}$ and a photoperiod of 16:8 (L:D) h. The adults were then removed and the offspring counted (50 nymphs were retained per plant) and allowed to develop on the plants for four additional days before the beginning of each experiment. If the number of nymphs was less than 50 per plant, the adults were kept on the leaves for another $12 \mathrm{~h}$ until they produced a total of 50 nymphs.

\section{Screening bioassay}

Two millilitres of conidia suspension $\left(10^{7}\right.$ conidia $\left.\mathrm{ml}^{-1}\right)$ of each isolate was applied by a handheld sprayer onto the 4-week-old potted cucumber, which contained 50 third instar nymphs. A formulation of B. bassiana (Naturalis- $\mathrm{L}^{\circ}$ by Fargro Ltd., UK) was included in the tests as a reference. Controls were sprayed with sterile $0.001 \%$ aqueous Tween 80 without conidia. The cucumber plants were air-dried on a bench top at room temperature for $1 \mathrm{~h}$. Each cucumber leaf was cut from the treated cucumber plant and was placed on a 9-cm Petri dish that had a dampened filter paper on the bottom and 1-cm hole covered with nylon mesh on the lid. The Petri dishes were randomly placed in Plexiglas cages $(35 \times 40 \times 35 \mathrm{~cm})$ and were maintained at $20 \pm 1{ }^{\circ} \mathrm{C}, \geq 90 \% \mathrm{RH}$ and a photoperiod of 16:8 (L:D) h. Aphid mortality was recorded after 1, 3, 5 and 7 days. Dead aphids were surface sterilised by rinsing twice with $70 \%$ ethanol for $30 \mathrm{~s}$ and then with sterilised distilled water and thereafter placed on water agar ( $3 \mathrm{~g}$ of agar/l of water) in Petri dishes for 5 days to confirm infection by EPF (Mohammed and Hatcher 2016). A cadaver was regarded as dead from infection by these fungi if the conidia were recovered from it. The entire experiment was repeated three times, giving a total of 30 replicates per treatment for each aphid species.

\section{Multiple-dose bioassays of selected isolates against aphid nymphs}

L. lecanii was selected, based on results of the single-dose screen, for more detailed multiple-dose bioassays against $M$. persicae and A. gossypii (highly susceptible aphid species). This experiment followed the method described in the 'Screening bioassay' section, except that the suspensions of L. lecanii sprayed onto cucumber plants contained different concentrations of conidia $\left(1 \times 10^{4}, 1 \times 10^{5}, 1 \times 10^{6}, 1 \times 10^{7}\right.$, or $1 \times 10^{8}$ conidia $\mathrm{ml}^{-1}$ ). Aphid mortality rate was recorded after 1,3 , 5 and 7 days. The entire experiment was repeated twice, giving a total of 20 replicates per treatment for each aphid species.

Efficacy of $L$. lecanii against $M$. persicae and A. gossypii on cucumber in the greenhouse

L. lecanii was identified as the most virulent EPF in the laboratory and was selected for further assessment in a greenhouse experiment on cucumber plants infested with $M$. persicae or A. gossypii. The experiment was carried out in $164 \times 6 \mathrm{~m}$ greenhouses from 6 February until 10 May 2017 at the Faculty of Agriculture, University of Kufa, Iraq. The treatments were as follows: (1) plants infested with $M$. persicae and exposed to L. lecanii: $20 \mathrm{ml}$ per plant containing $1 \times 10^{8}$ conidia $\mathrm{ml}^{-1}$, applied using a Diaphragm CP 15 sprayer (Agratech NW Ltd, Waterfoot, Lancashire, UK); (2) plants infested with $A$. gossypii and exposed to L. lecanii similar to (1); (3) plants infested with M. persicae and exposed to $20 \mathrm{ml}$ of sterile water and $0.02 \%$ Tween 80 per plant (control); and (4) plants infested with A. gossypii and exposed to water and Tween 80 similarly to (3) (control). Each treatment was replicated four times in a randomised complete block design. Each of the four blocks included four different treatment plots, and each plot (consisting of 40 plants) was contained in one greenhouse. The average high and low daily temperature and relative humidity were recorded using a data logger (Tinytag Explorer 4.8, Gemini Data Loggers (UK) Ltd., Chichester, UK), and these were $28.9 \pm 3.2{ }^{\circ} \mathrm{C}$ and $14.2 \pm 2.1{ }^{\circ} \mathrm{C}$, and 93.5 and $40.8 \% \mathrm{RH}$, respectively, during the experiment.

\section{Statistical analysis}

Statistical analyses were carried out using GenStat (version 16; VSN International, Hemel Hempstead, UK). Normality of data distribution was estimated using a Shapiro-Wilk test ( $W$ test). The data were transformed using arcsine square root when it was necessary to meet the assumption of normality. For the screening test, aphid mortality data were corrected for natural death in the control using Abbott's formula (Abbott 1925), then analysed using a generalised linear model with binomial errors. The effect of conidial concentration on the mortality of $M$. persicae and $A$. gossypii was analysed separately for each aphid species using a generalised linear model with binomial errors. For the greenhouse experiment, one-factor repeated measurement analysis ANOVA was used to determine the effect of $L$. lecanii against each aphid species. Mean comparisons were performed using Tukey's test at $5 \%$ level of significance $(P<0.05)$.

\section{Results and discussion}

\section{Screening tests}

The results of a bioassay to determine the virulence of various EPF at $10^{7}$ conidia $\mathrm{ml}^{-1}$ against $M$. persicae, A. gossypii, A. fabae and M. euphorbiae are depicted in Fig. 1. Corrected mortality varied according to the fungal isolate $\left(F_{(4,140)}=95.72 ; P<0.001\right)$ and aphid species $\left(F_{(3,140)}=69.59 ; P<0.001\right)$. L. lecanii originally isolated from an aphid was the most virulent one, among those tested, with the others 


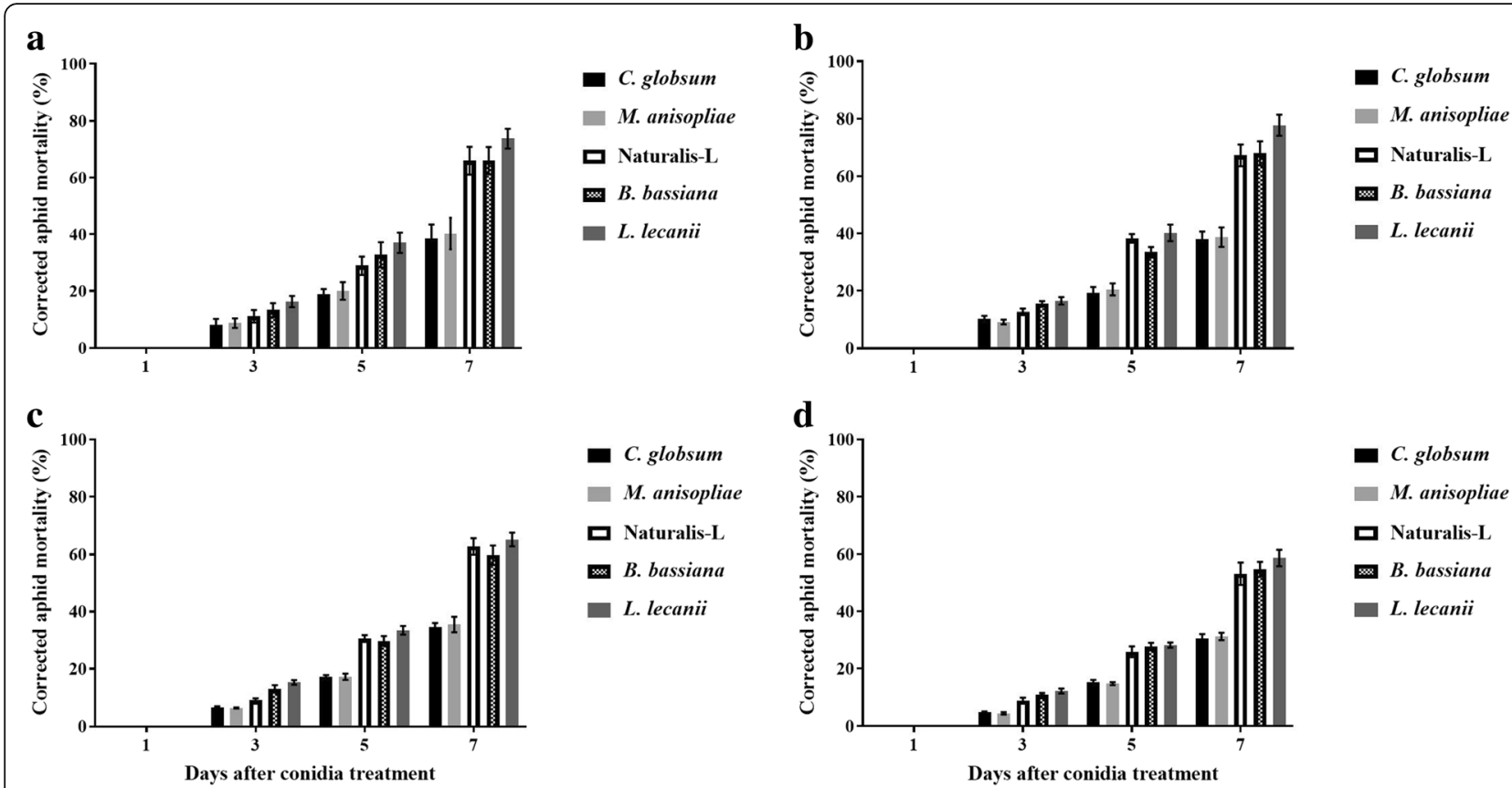

Fig. 1 The corrected mortalities (mean \pm SE) of a A. gossypii, b M. persicae, $\mathbf{c}$ A. fabae and $\mathbf{d}$ M. euphorbiae treated with conidia of four isolates of entomopathogenic fungi and commercial formulation (Naturalist ${ }^{\circledR}$ ) at $20{ }^{\circ} \mathrm{C}$ and $80 \% \mathrm{RH}$. The conidial concentration of each fungal isolate used for treatment was $1 \times 10^{7}$ conidia $\mathrm{ml}^{-1}$

being collected from the sunn pest, beetles and moths (Table 1). For control of M. persicae, L. lecanii caused $80 \%$ mortality in 7 days, while the other fungal isolates including commercially registered isolate $B$. bassiana ATCC 74040 attained 35-67\% (Fig. 1a). For A. gossypii control, L. lecanii induced $82 \%$ corrected mortality in 7 days, whereas the other fungal strains induced a corrected mortality ranged between 50 and $72 \%$ at the same time (Fig. 1b). For A. fabae and $M$. euphorbiae controls (Fig. 1c, d), the virulence of $L$. lecanii, B. bassiana and Naturalis-L were insignificantly different $(P>0.05)$, but were significantly higher than those of $M$. anisopliae and C. globosum $(P<0.05)$. Aphid mortality rate in control treatments ranged between 4 and $7 \%$.

In this study, L. lecanii was originally isolated from an aphid host, supporting the hypothesis that fungal strains isolated from closely related insect hosts would have higher efficacy than isolates from phylogenetically distant hosts. This confirms the findings of Vu et al. (2007) who reported that the virulence of strains $L$. lecanii 41185 and 6541, which were originally isolated from aphid hosts, were significantly higher than those of the other tested fungi for both M. persicae and A. gossypii.

To be a successful candidate for use in greenhouse crops, isolates should provide effective control of multiple aphid species. The results of the present study indicated that efficacy of EPF depends not only on the tested isolate but also on the target aphid species, where $M$. persicae and A. gossypii were more susceptible than $A$. fabae and M. euphorbiae to infection with tested isolates under laboratory conditions (Fig. 1). Similarly, Harper and Huang (1986) found that $V$. lecanii caused a 6090\% mortality of Aphis pisum, 32-85\% of M. dirhodum, that of M. persicae by $50-100 \%$ and that of Trialeurodes maculate by $37-75 \%$. In addition, Helen et al. (2003) reported that $A$. fabae was more susceptible than $M$. persicae to the infection with the same fungus in the same environmental conditions.

\section{Effect of conidial concentration on mortality of $M$. persicae and A. gossypii}

L. lecanii was chosen to examine the effect of various conidial concentrations on the mortality rate of $M$. persicae and A. gossypii. The results showed that conidial concentration of $L$. lecanii significantly affected the mortality rate of both aphid species 7 days post-spraying $\left(M\right.$. persicae $F_{(3,105)}=134.05 ; P<0.001$; A. gossypii $\left.{ }_{(3,105)}=124.37 ; P<0.001\right)$. The control values for aphids treated with $1 \times 10^{8}$ conidia $\mathrm{ml}^{-1}$ were much higher than those of $1 \times 10^{7}, 1 \times 10^{6}, 1 \times$ $10^{5}$ and $1 \times 10^{4}$ conidia $\mathrm{ml}^{-1}$ for both $M$. persicae and A. gossypii (Fig. 2). The interactions between fungus concentration and time after application were not significantly different $(P \geq 0.05)$. Aphid mortality rate in control treatments ranged between 4 and 7.6\%.

It is very important to determine the optimal concentration of fungal conidia for spray applications to reduce 

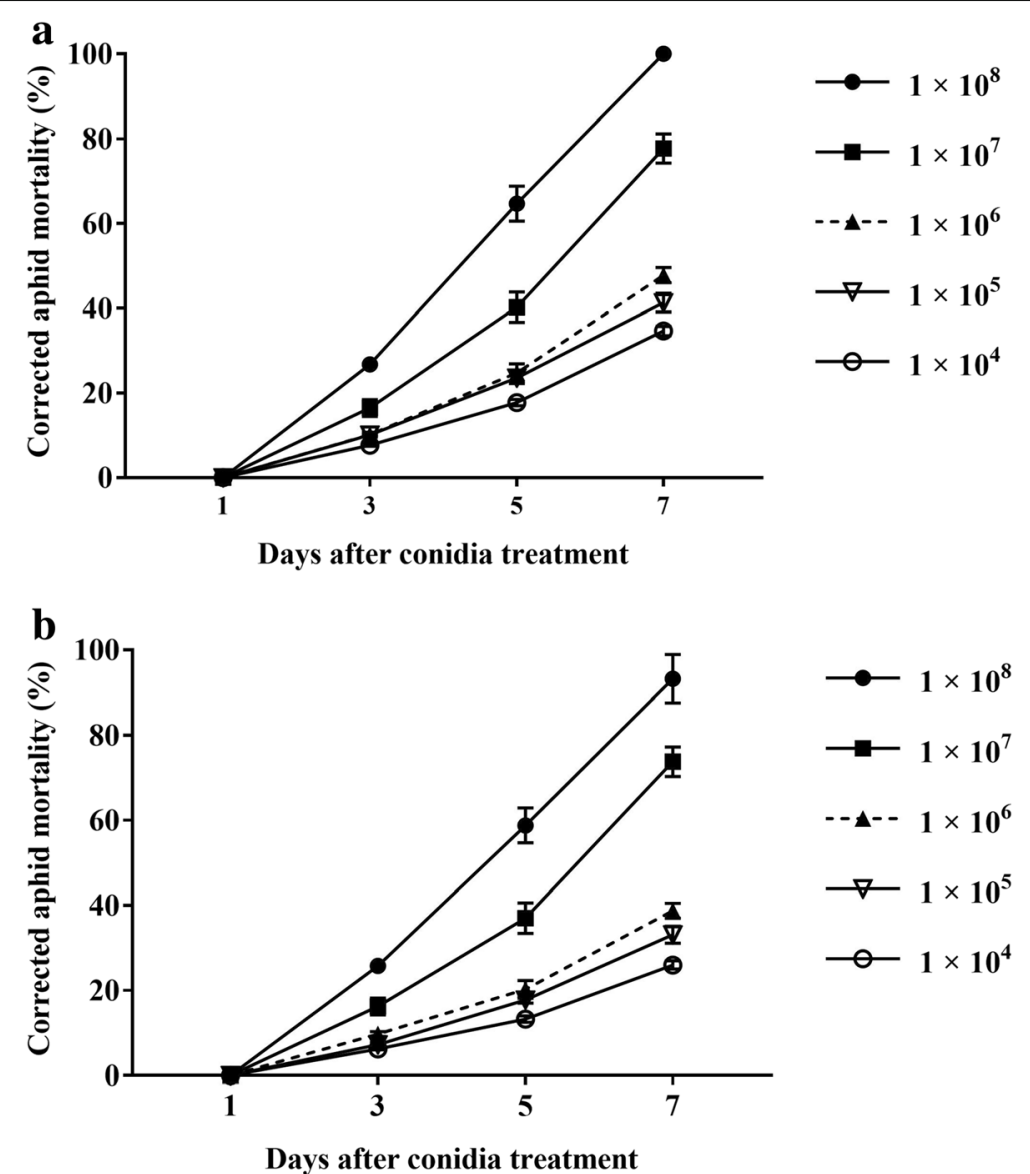

Fig. 2 The effect of conidial concentration of L. lecanii isolate and days after fungal application on the cumulative mortalities ( \pm SE) of a M. persicae and $\mathbf{b}$ A. gossypii

the overall cost of insect pest control while achieving a high level of control. The results of the present study showed that $1 \times 10^{8}$ conidia $\mathrm{ml}^{-1}$ was the recommended dosage to spray to control aphids under greenhouse or field conditions. The results obtained in the present study are consistent with those of $\mathrm{Vu}$ et al. (2007) who reported that the control values for $M$. persicae treated with $1 \times 10^{8}$ conidia $\mathrm{ml}^{-1}$ of $L$. lecanii 41185 were much higher than those of $1 \times 10^{6}$, $1 \times 10^{5}$ and $1 \times 10^{4}$ conidia $\mathrm{ml}^{-1}$.

\section{Efficacy of L. lecanii against $M$. persicae or A. gossypii in the greenhouse}

Before exposure to L. lecanii, there was insignificant difference in the number of aphids in cucumber plants infested with either $M$. persicae or A. gossypii in all greenhouses $\left(F_{(1,48)}=0.81 ; P=0.544\right)$. Plants that were treated by $L$. lecanii showed a significant reduction in the number of $M$. persicae $\left(F_{(1,48)}=44.24 ; P<0.001\right)$ and $A$. gossypii $\left(F_{(1,48)}=41.83 ; P<0.001\right)$ between 5 and 20 days post-spraying, compared with the control treatment (Fig. 3).
The greenhouse results further supported the efficacy of L. lecanii in the laboratory, resulting in a reduction of aphid population for both A. gossypii and M. persicae significantly higher than the controls. The significant reduction in aphid populations was not evident until 5 days post-treatment; it lasted for a week, and then, aphid populations began increasing again. This time lag in the onset of insect mortality was similar for other studies with L. lecanii or other isolates of EPF (Kim et al. 2007; Wu et al. 2013). There are two possible reasons to explain the short-term effect of fungal treatment in reducing aphid populations in the greenhouse. One of the most important limitations in the use of EPF for the control of insect pests, which explain the short-term effect of fungal treatment in reducing aphid populations under greenhouse conditions, is that poor environmental conditions such as high or low temperature, UV light, rainfall and relative humidity during the treatment period are known to affect spore germination and penetration of the aphid host by entomopathogenic fungi (Mohammed and Hatcher 2016) and/or the persistence of the conidia applied on foliage (Maniania et al. 2003). For example, Daoust and Pereira (1986) reported that conidia of M. anisopliae and $B$. 

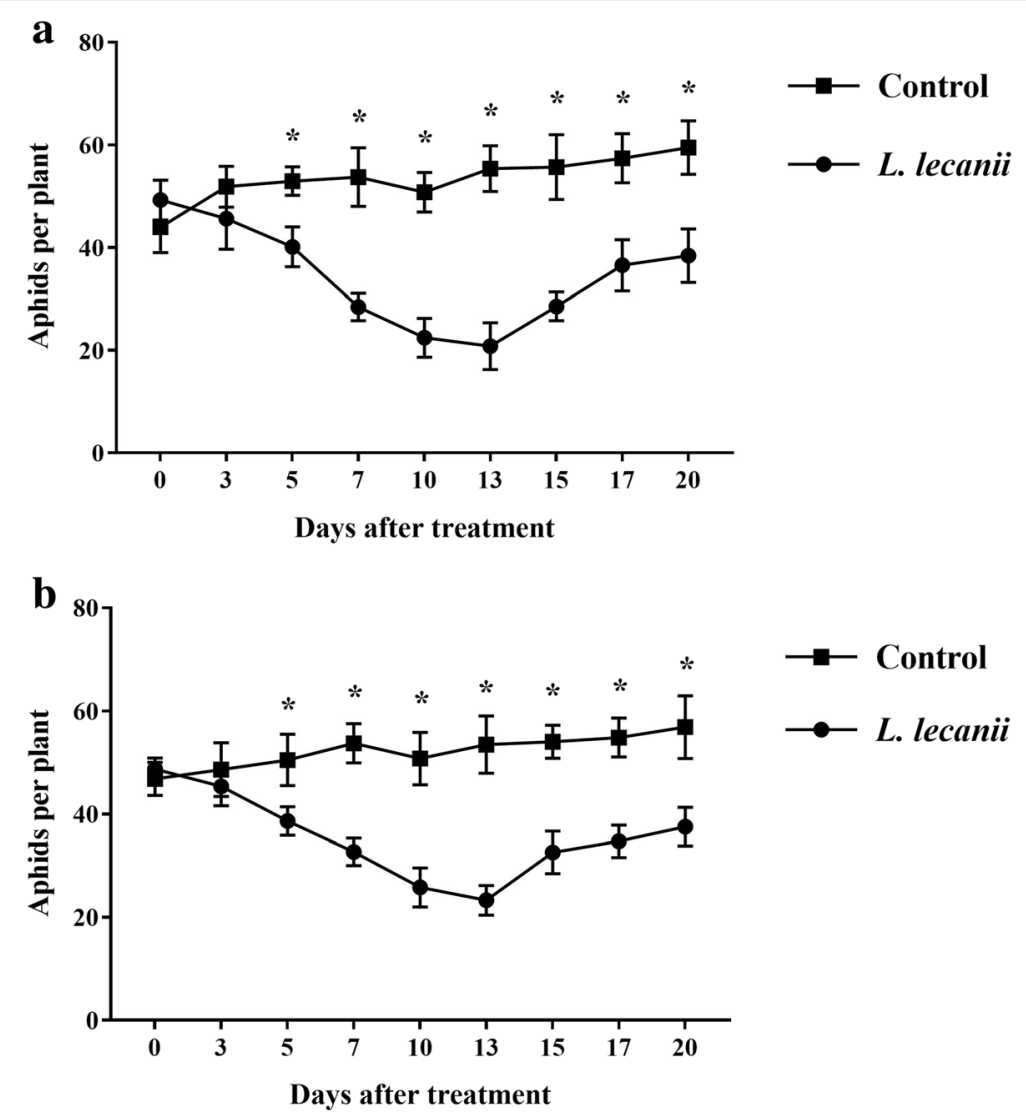

Fig. 3 Effect of L. lecanii isolate $\left(1 \times 10^{8}\right.$ conidia $\left.\mathrm{ml}^{-1}\right)$ on the numbers of a M. persicae and $\mathbf{b}$ A. gossypii (mean \pm SE) compared with the control on cucumber plants at different days post-treatment in the greenhouse. Bars represent the standard errors of the means. Treatments marked with asterisks are significantly different from the corresponding control in the values at $P<0.05$, using Tukey's test

bassiana persisted for only 12 days on cowpea leaves after application. In addition, Shrestha et al. (2015) found that the cumulative percentage decline in the conidial population of $B$. bassiana was (92\%) within 11 days post-spraying. Although persistence was not tested in the present study, obtained results suggested that $L$. lecanii was able to persist for 2 weeks in the greenhouse after spraying. Based on these observations, application of L. lecanii every 2 weeks could provide a potential control of both A. gossypii and M. persicae populations on greenhouse crops.

\section{Conclusions}

Obtained results showed that an Iraqi domestic isolate of $L$. lecanii was the most virulent to both $A$. gossypii and $M$. persicae populations in the laboratory and under greenhouse conditions when applied at a rate of $1 \times 10^{8}$ conidia $\mathrm{ml}^{-1}$. These results suggested that this isolate had the potential for development as a microbial biopesticide and can be included in integrated pest management programs designed for controlling the populations of green peach and cotton aphids in Iraqi agricultural systems.

\section{Acknowledgements}

The authors wish to thank the Laboratory of Fungi, Plant Protection Department, Faculty of Agriculture, University of Kufa, for providing us with the entomopathogenic fungi used in this study. The authors are grateful to Mrs. Viv Rimmer, School of Biological Sciences, University of Reading, for the editorial and language assistance.

Availability of data and materials

All data and materials are available.

Authors' contributions

ZNAK and JHK designed and supervised all the experiments. AAM carried out the experiments, recorded the data and interpreted the results. ZNAK and JHK analysed the data and AAM wrote the manuscript. All authors read and approved the final manuscript.

Ethics approval and consent to participate Not applicable.

Consent for publication Not applicable.

\section{Competing interests}

The authors declare that they have no competing interests.

\section{Publisher's Note}

Springer Nature remains neutral with regard to jurisdictional claims in published maps and institutional affiliations. 


\section{Author details}

${ }^{1}$ Plant Protection Department, University of Kufa, Najaf, Iraq. ${ }^{2}$ Department of Field Crops, Al-Qasim Green University, Babylon, Iraq

Received: 22 May 2018 Accepted: 23 August 2018

Published online: 04 September 2018

\section{References}

Abbott WS (1925) A method of computing the effectiveness of an insecticide. J Econ Entomol 18:265-267

Bielza P (2008) Insecticide resistance management strategies against the western flower thrips, Frankliniella occidentalis. Pest Manag Sci 64:1131-1138

Blackman RL, Eastop VF (2000) Aphids on the world's crop: an identification and information guide. Wiley, Chichester

Blackman RL, Eastop VF (2007) Taxonomic issues. In: van Emden HF, Harringto R (eds) Aphids as crop pests. CABI, Wallingford, pp 1-22

Chan CK, Forbes AR, Raworth DA (1991) Aphid-transmitted viruses and their vectors of the world. Research Branch, Agriculture Canada, Vancouver

Daoust RA, Pereira RM (1986) Stability of entomopathogenic fungi Beauveria bassiana and Metarhizium anisopliae on beetle-attracting tubers and cowpea foliage in Brazil. Environ Entomol 15:1237-1243

Dorschner KW, Feng MG, Baird CR (1991) Virulence of an aphid-derived isolate of Beauveria bassiana (Fungi: Hyphomycetes) to the hop aphid, Phorodon humuli (Homoptera: Aphididae). Environ Entomol 20:690-693

Faria MR, Wraight SP (2007) Mycoinsecticides and mycoacaricides: a comprehensive list with worldwide coverage and international classification of formulation types. Biol Control 43:237-256

Gao YL, Lei ZR, Reitz SR (2012) Western flower thrips resistance to insecticides: detection, mechanisms, and management strategies. Pest Manag Sci 68: $1111-1121$

Hajek AE, St Leger RJ (1994) Interaction between fungal pathogens and insect hosts. Annu Rev Entomol 39:293-332

Harper AM, Huang HC (1986) Evaluation of the entomophagous fungus Verticillium lecanii (Moniliales: Moniliaceae) as a control agent for insects. Environ Entomol 15:281-284

Helen Y, Pell JK, Alderson PG, Clark SJ, Pye BJ (2003) Laboratory evaluation of temperature effects on the germination and growth of entomopathogenic fungi and on their pathogenicity to two aphid species. Pest Manag Sci 59: 156-165

Jasman AK, Slomy AK, Abed SH, Kadhem TK (2016) Evaluation of the efficiency of some plant extracts and spore suspension Beauveria bassiana to control Myzus persicae (sulzer) (Aphididae: Homoptera) on the pepper plant. Euphrates J Agri Sci 8:213-221 Arabic

Kim JJ, Goettel MS, Gillespie DR (2007) Potential of Lecanicillium species for dual microbial control of aphids and the cucumber powdery mildew fungus Sphaerotheca fuliginea. Biol Control 40:327-332

Kim JJ, Kim KC (2008) Selection of a highly virulent isolate of Lecanicillium attenuatum against cotton aphid. J Asia Pac Entomol 11:1-4

Latgé JP, Papierok B (1988) Aphid pathogen. In: Minks AK, Harrewijin P (eds) Aphid their biology, natural enemies and control, 2B. Elsevier, Amsterdam, pp 323-364

Li W, Sheng C (2007) Occurrence and distribution of entomophthoralean fungi infecting aphids in mainland China. Biocontrol Sci Tech 17:433-439

Maniania NK, Sithanantham S, Ekesi S, Ampong-Nyarko K, Baumgärtner J, Löhr B, Matoka CM (2003) A field trial of the entomogenous fungus Metarhizium anisopliae for control of onion thrips, Thrips tabaci. Crop Prot 22:553-559

Mesquita A, Lacey LA, Mercadier G, LeClant F (1996) Entomopathogenic activity of a whitefly derived isolate of Paecilomyces fumosoroseus (Deuteromycotina: Hyphomycetes) against the Russian wheat aphid, Diuraphis noxia (Homoptera: Aphididae) with the description of an effective bioassay method. Eur J Entomol 93:69-75

Milner RJ (1997) Prospects for biopesticides for aphid control. Entomophaga 42: 227-239

Mohammed AA, Hatcher PE (2016) Effect of temperature, relative humidity and aphid developmental stage on the efficacy of the mycoinsecticide Mycotal ${ }^{\circledR}$ against Myzus persicae. Biocontrol Sci Tech 26:1379-1400

Roy H, Baverstock J, Chamberlain K, Pell J (2005) Do aphids infected with entomopathogenic fungi continue to produce and respond to alarm pheromone? Biocontrol Sci Tech 15:859-866

Shrestha G, Enkegaard A, Steenberg T (2015) Laboratory and semi-field evaluation of Beauveria bassiana (Ascomycota: Hypocreales) against the lettuce aphid, Nasonovia ribisnigri (Hemiptera: Aphididae). Biol Control 85:37-

Tarek AM (2013) Compared the efficiency of botanical extract Oxamatrin and Bioinsecticide Abamectin to controlling Myzus persicae aphid insect on hybrid eggplant Solanum melongena in greenhouses. Al-Anbar J Agri Sci 11:359-369 Arabic

Vandenberg J (1996) Standardized bioassay and screening of Beauveria bassiana and Paecilomyces fumosoroseus (Deuteromycotina: Hyphomycetes) against Russian wheat aphid (Homoptera: Aphididae). J Econ Entomol 89:1418-1423

Vu VH, Hong SI, Kim K (2007) Selection of entomopathogenic fungi for aphid control. J Biosci Bioeng 104:498-505

Wu S, Gao Y, Xu X, Zhang Y, Wang J, Lei Z, Smagghe G (2013) Laboratory and greenhouse evaluation of a new entomopathogenic strain of Beauveria bassiana for control of the onion thrips Thrips tabaci. Biocontrol Sci Tech 23: 794-802

Zaki FN (1998) Efficiency of the entomopathogenic fungus, Beauveria bassiana (Bals), against Aphis crassivora Koch and Bemesia tabaci, Gennandius. J Appl Entomol 122:397-399

\section{Submit your manuscript to a SpringerOpen ${ }^{\circ}$ journal and benefit from:}

- Convenient online submission

- Rigorous peer review

- Open access: articles freely available online

- High visibility within the field

- Retaining the copyright to your article

Submit your next manuscript at $>$ springeropen.com 